\title{
THE USE OF FINGER-PRINTS IN QUESTIONED PATERNITY SUITS
}

THE HEREDITY OF PAPILLARY PATTERNS. Sándor Ökrös, M.D. (Director of the Forensic Medicine Institute, Medical University, Budapest). Translated by A. Herczeg. 1965.

The title of the book is misleading and, consequently, the contents are largely disappointing from a genetical point of view. Dr Ökrös does not mention any of the advances in our knowledge of the inheritance of dermatoglyphic characters made in the last 20 years. Moreover, the book is limited to fingerprint characteristics. The author's interest is the use of fingerprints in questioned paternity suits. The contents, therefore, are primarily of legal interest.

Dr Ökrös describes the results of his work in the field over a period of 18 years and uses a series of cases of questioned paternity. The descriptions include his method of studying finger-prints from cellophane dactylograms and his method of classifying finger-print patterns into 95 types, abbreviated to 60 for practical use. Unfortunately, we still do not know how such patterns are inherited. The most recent and interesting of the author's findings is that the detailed ridge structure of a child shows some of the characteristics of both parents. From a study of the minutiae on homologous fingers it is claimed that the parentage of a child can be definitely established. The method has been used successfully in well over 1000 paternity lawsuits. Minutiae findings in 29 cases are given in detail with illustrations. However, of approximately 40 parental minutiae only one or two, seldom three, are found in the offspring. The author stresses that " much effort and great experience are needed to assess the findings" and he admits that in a few instances his conclusions do not agree with evidence from blood groups.

S. B. Holt

The Galton Laboratory, Department of Human Genetics and Biometry, University College, Gower Street, London, W.C.1

\section{BEHAVIOR-GENETIC ANALYSIS. Edited by Jerry Hirsch. McGraw-Hill Series in Psychology.}

The last few years have seen a rapid increase in the number of behavioural scientists carrying out research into the genetics of behaviour. Behaviorgenetic Analysis, a multi-author book which grew out of a conference on behaviour genetics held at Stanford University during the summers of 196162 is mainly concerned with the part being played by the more biologically orientated among them. The text is divided into four main sections with a final chapter by the editor, Jerry Hirsch.

In the first section, "Behavior and Evolution", Caspari distinguishes two approaches to the study of evolution, the study of mechanisms causing evolution to occur and the tracing of phylogenetic changes caused by evolution. Both approaches are represented here. Washburn and Shirek, in what is necessarily a rather speculative contribution, discuss the importance of tool use in the evolution of bipedalism among the primates suggesting that the human brain may have evolved in response to the selection pressures 
created by the kinds of behaviour associated with these two activities. King, is also concerned with the two-way interaction between the gene pool and behaviour but rather in the short term. Using evidence from the ecological and developmental genetics of small mammals he suggests a number of possible mechanisms underlying evolutionary change. Manning does much the same thing for insects. The high point of this section, however, is the really splendid chapter on phylogenetic differences in the social behaviour of honeybees and related insects by Rothenbuhler in which an enormous amount of evidence is assessed in a skilful and highly readable manner. One of the implications of this section of the book which psychologists may well consider is the need for the characters investigated in behaviour-genetic studies to relate realistically to the ecology of the organisms concerned if evolutionary implications are to be drawn.

The second section describes work on "Genes and Mechanisms". Caspari provides a straightforward account of gene-action in which he shows that the mechanisms underlying behavioural phenotypes need, in principle, be no different from those underlying other phenotypes. The following three contributions, not surprisingly, support Caspari's contention. Ginsberg describes research on audiogenic seizures in mice, in which he is able to relate susceptibility to a series of apparently single gene effects with an identifiable physiological effect. Hamburg relates the genetics of adrenocortical function to its regulation by the central nervous system and Hsia describes the hereditary metabolic diseases. This section ends with a rather ill-fitting chapter by Eugene Roberts which presents a hypothetical synaptic model of brain processes susceptible of being related to the genome through the production of brain enzymes. The section very clearly demonstrates the need to identify major genes in order to trace gene mechanisms. The mechanisms underlying the ubiquitous polygenes remain hidden. One feels some correlational approach combining physiological and behavioural measurements in the kind of polygene analysis Thoday has developed might well extend this area.

Section three consists of an account of some of the methods of "Quantitative genetic analysis". It is in these methods that psychologists have recently become especially interested, though, to judge from the literature, they have been giving considerable difficulty! Part of the trouble seems to be the paucity of straightforward accounts of these methods to the non-specialist. The lucid chapter by R. C. Roberts should do much to clarify basic ideas, particularly for those already familiar with Falconer's excellent introduction, although it is a pity he has limited himself to random mating populations when so much experimental work in psychogenetics is done with inbred lines. Hirsch provides an introduction to chromosome assay techniques using his own work on geotaxis in Drosophila as an example. The contribution by Bruell on "Behavioral Heterosis" seems to reflect, unfortunately, the difficulties with biometrical genetics referred to earlier. With the excellent aim of relating the genetic architecture revealed by a diallel cross to the kind of selective forces which have acted on the organism in the past he proposes an analysis consisting merely of a graphical representation of the raw data showing the score of each $F_{1}$ in relation to its respective parents. While such a device may be useful for a preliminary look at the data it can hardly be taken seriously as a substitute for the full statistical analysis required to elucidate the genetic control underlying the character. The contribution 
by Broadhurst provides a very clear "Introduction to the Diallel Cross" for the case of a fixed sample of inbred lines. This chapter is a valuable contribution to the book in that it sets out simply the way to carry out and evaluate a diallel cross and shows the variety of information obtainable from the method.

The fourth section of the book is concerned with "Conceptual and Methodological Problems" peculiar to the area. McClearn stresses the importance that psychologists realise that genetic diversity implies the search for general laws applicable to all individuals is probably doomed from the outset and DeFries goes on to make the same point and review some of the behaviour-genetic literature which clearly illustrates the great variety of behaviours to which this warning applies. Behaviour genetics has borrowed heavily from genetics, and in a short chapter R. C. Roberts asks what behaviour genetics has to offer genetics in return. He decides that considerable potential value lies in providing diverse characters for the testing of genetic theory, so far based on a very narrow range of characters only and also in the insight into the evolution of behaviour it may provide through the study of genetic architecture. This latter approach is, of course, already being actively pursued by a number of workers in this area and is that suggested in the chapter by Bruell. One of the most thoughtful chapters in this book is Thompson's " Some problems in the genetic study of personality and intelligence". He emphasises that beliaviour genetics is not just another branch of genetics. Since the characters studied are of primary interest, the goal is to understand how behaviour works, not the genetic system. He proceeds with a penetrating account of the futile attempts of factor analysis to associate factors with the genetic units of behavioural traits and makes valuable suggestions for the application of alternative multivariate techniques to the same problem. Since the compilation of this book a serious attack on this problem has, in fact, been made using multivariate genetic analysis of variance and the analysis of components of genetic covariance by Vandenberg and by Loehlin with an already encouraging measure of success. Thompson also discusses the fluidity of behavioural traits, suggesting that the systematic change of the genetic control of traits with time, formally the interaction of genotype and environment, represents one of the most important problems for study in the whole of behaviour genetics. This chapter, contains a number of ideas for future research. The chapter by Spuhler and Lindzey on "Racial differences in Behavior" is informative about major genes and simple sensory processes but as far as more complex behavioural characters are concerned comes to the conclusion that "the concept of race has little importance for the student of human behaviour at present".

The final chapter in this book is an "overview" and "synthesising commentary" by the editor. Unfortunately, although it is highly readable it contains a number of rather exaggerated and negative criticisms of the current methodology in behaviour genetics. He suggests, for example, that the frequent finding of the $F_{2}$ variance not exceeding that of the nonsegregating generations is due, in the case of the rat say, to inadequate sampling of a four trillion cell matrix of possible genotypes. How then, one wonders, is it that replicable estimates of genetic variance have in fact been obtained? How, indeed, has quantitative genetics been a practical proposition at all! Clearly the possibility of a four trillion cell matrix of possible 
genotypes is not relevant to the decision as to what constitutes a realistic sample size. In fact, as Bruell showed in the "Roots of Behavior" symposium employing formulae from Mather's Biometrical Genetics whether or not segregation is observed in the $F_{2}$ will depend on the heritability, the difference between the extreme homozygotes and the number of genes. Much simpler explanations of this $F_{2}$ phenomenon, in terms of differential stability between $\mathrm{F}_{2}$ and non-segregating generations, or inadequate scales are not discussed. There is a similar misconception concerning the size of a diallel cross necessary for valid statistical inference. Hirsch agrees with Bruell that this must be very large indeed. In fact, for a fixed sample analysis there is no requirement as regards the size of the sample. The question is irrelevant. In the analysis of a random sample Hayman suggests that from 8 to 10 lines is a reasonable minimum. Certainly there are problems concerning the interpretation of diallel crosses but this is not one of them.

The arguments concerning genotype-environment interaction are similarly exaggerated as are those concerning the importance of the assumptions underlying the analysis of variance which, in fact, relate, more to the problems of significance testing than to those of estimation, which are of more importance in quantitative genetics. While there is much good sense, too, in this chapter, Hirsch arouses concern lest confusion in an already confused area be increased. Perhaps some measure of exaggeration is the price one pays in striving for a compelling style.

The book is extremely well indexed and contains a bibliography apparently complete up until 1964-65. It can be thoroughly recommended to those wishing to familiarise themselves with a goodly part of recent behaviour genetics.

D. W. Fulker

P.O. Box 363, Department of Psychology, Birmingham 15

REPRODUCTION AND MAN. R. J. Harrison. CHEMICAL EXCHANGES IN MAN, A PHYSIOLOGICAL ESSAY. B. F. Mathews. Volumes 3 and 10 in the "Contemporary Science Paperback "Series. Oliver and Boyd: Edinburgh and London. Each pp. viit 134. 7s. 6d.

These volumes form part of a new series which is intended for first and second year undergraduates, and for scientists reading outside their own fields. Both books are short and readable. The first one gives a clear description of the anatomy and physiology of reproduction in man and other mammals, and relates them to the world's population problems. The second book is a lucid account of how the body regulates its $\mathrm{pH}$ and the concentrations of oxygen, carbon dioxide, water and electrolytes in its tissues. The chemical exchanges involved in the digestion and absorption of food from the gut are not included. Both books have indexes and suggestions for further reading and are illustrated with many line drawings. In addition, Professor Harrison's book contains 16 pages of excellent photographs. It is a pity that these completely lack any indications of scale.

J. G. M. Shire

University of Cambridge, Department of Genetics 